\title{
Strategi Promosi Kesehatan Dalam Upaya Rehabilitasi Penyalahgunaan Narkoba Oleh Badan Narkotika Nasional Provinsi (BNNP) Maluku Utara Tahun 2019
}

\author{
Namira ${ }^{1}$, Ramli $^{\circledR}{ }^{\bowtie a n}$ Agustin Rahayu ${ }^{2}$ \\ 1 Mahasiswa Peminatan PKIP Fakultas Ilmu Kesehatan, Universitas Muhammadiyah Maluku Utara. Ternate. Indonesia, \\ Email : namiraira16@gmail.com \\ 2 Staf Pengajar Fakultas Ilmu Kesehatan, Universitas Muhammadiyah Maluku Utara. Ternate. Indonesia, \\ Email : ramli.rijal88@gmail.com, agustinyayu21@gmail.com \\ Korespondensi : Ramli, Universitas Muhammadiyah Maluku Utara, Ternate, Indonesia, \\ Email : ramli.rijal88@gmail.com
}

\begin{abstract}
ABSTRAK.
Undang-Undang Narkotika Nomor 35 Tahun 2009 mengamanahkan dilakukannya proses wajib lapor pecandu narkotika ke Puskesmas, Rumah Sakit, atau lembaga rehabilitasi medis dan lembaga rehabilitasi sosial yang ditunjuk oleh pemerintah untuk mendapatkan pengobatan dan perawatan. Pelaksanaan proses wajib lapor memerlukan koordinasi antara instansi-instansi yang terkait dengan dukungan dari masyarakat sehingga dapat mencapai hasil yang optimal (BNN RI, 2014). Penelitian ini bertujuan untuk mendapatkan informasi terkait Advokasi, Kemitaraan dan Pemberdayaan dalam Upaya Rehabilitasi Penyelahgunaan Narkoba di BNNP Maluku Utara. Jenis penelitian yang digunakan adalah penelitian Kualitatif, pengumpulan data melalui wawancara mendalam, penentuan informan dilakukan dengan tehnik purposive sampling dan jumlah informan sebanyak 4 orang dengan rincian 2 informan pegawai BNNP Maluku Utara dan 2 informan pegawai Lapas Kelas IIA Ternate. Berdasarkan hasil penelitian terkait Advokasi adanya dukungan dari berbagai pihak, diantaranya : Lapas Kelas IIA Ternate, Puskesmas Kalumata, RSUD Dr. Hasan Boesoirie, Klinik Pratama, LSM Rorano, dan lain-lain. Bentuk Kemitraan BNNP Malut dirumuskan dalam surat Perjanjian Kerja Sama (PKS) antar institusi, diantaranya : Perjanjian Kerjasama antara Bidang Rehabilitasi BNNP Maluku Utara dengan Lapas Kelas IIA Ternate tentang dukungan layanan Rehabilitasi bagi pecandu dan korban penyalahgunaan Narkoba, Perjanjian Kerjasama dengan Puskesmas Kalumata tentang dukungan Pelayanan Rehabilitasi bagi pecandu dan korban Penyalahgunaan Narkotika pada fasilitas pemerintah. Adapun kegiatan Pemberdayaan melakukan penyuluhan dan pelatihan untuk memotivasi klien agar mengikuti layanan program rehabilitasi dan mengasah ketrampilan yang dimiliki klien sesuai bakat dan minat. Kendala yang ditemukan kurangnya pengguna melapor diri secara sukarela, sumber daya terbatas dan kurangnya sarana prasarana pendukung lainnya. Disarankan kepada Bidang Rehabilitasi BNNP Maluku Utara agar selalu melakukan penyuluhan dan memotivasi pengguna sehingga mereka secara sukarela melakukan rehabilitasi narkoba, menyediakan rumah damping, dan alat transportasi seperti bus dan speed boat.
\end{abstract}

Keyword: Strategi, Promosi, Kesehatan, Rehabilitasi, Narkoba

\section{PENDAHULUAN}

\subsection{Latar Belakang}

Pembangunan kesehatan pada hakekatnya adalah upaya yang dilaksanakan oleh semua komponen Bangsa Indonesia yang bertujuan untuk meningkatkan kesadaran, kemauan, dan kemampuan hidup sehat bagi setiap orang agar terwujud derajat kesehatan masyarakat yang setinggitingginya, sebagai investasi bagi pembangunan sumber daya manusia yang produktif secara sosial dan ekonomis. Keberhasilan pembangunan kesehatan sangat ditentukan oleh kesinambungan antar upaya program dan sektor, serta kesinambungan dengan upaya-upaya yang telah dilaksanakan oleh periode sebelumnya (Kemenkes RI, 2015). 
Pada tahun 1998, sesi khusus pada pertemuan sidang Perserikatan Bangsa-Bangsa (PBB) bersepakat untuk bekerjasama dalam "membrantas atau mengurangi dengan signifikan" produksi narkotika illegal dan penyalahgunaannya pada tahun 2019. Hal ini tentu bukannya target yang mudah dicapai. United Nations Office on Drugs and Crime (UNODC) mencatat bahwa sebagian negara-negara di dunia ada yang telah mampu mengontrol situasi masalah narkotikanya dalam kurun waktu yang relatif singkat, namun sebagian besar justru tidak atau belum mampu mengontrol situasi tersebut.

Undang-Undang Narkotika No. 35/2009 mengamanahkan dilakukannya proses wajib lapor pecandu narkotika ke Puskesmas, Rumah Sakit, dan/atau lembaga rehabilitasi medis dan lembaga rehabilitasi sosial yang ditunjuk oleh pemerintah untuk mendapatkan pengobatan dan perawatan. Untuk mendukung pelaksanaan wajib lapor ini disusunlah Peraturan Pemerintah tentang Wajib Lapor Pecandu Narkotika dan Peraturan Menteri Kesehatan tentang Rehabilitasi Medis Pecandu, Penyalahguna dan Korban Penyalahgunaan Narkotika. Pelaksanaan proses wajib lapor memerlukan koordinasi antara instansi-instansi yang terkait dengan dukungan dari masyarakat sehingga dapat mencapai hasil yang optimal (BNN RI, 2014).

Penyalahgunaan narkoba saat ini sudah menjadi masalah global yang mengakibatkan dampak buruk pada berbagai bidang kehidupan masyarakat dan bangsa meliputi aspek kesehatan, pendidikan, pekerjaan, kehidupan sosial, dan keamanan. Berdasarkan hasil penlitian BNN bekerjasama dengan Puslitkes UI Tahun 2014 tentang Survei Nasional Perkembangan Penyalahgunaan Narkoba di Indonesia, diketahui bahwa angka prevalensi penyalahguna narkoba di Indonesia telah mencapai 2,18\% atau sekitar 4,02 juta orang dari total pupulasi penduduk (berusia 10-59 tahun). Tahun 2015 jumlah penyalah guna Narkoba diproyeksikan $\pm 2,8 \%$ atau setera dengan $\pm 5,1-5,6$ juta jiwa populasi penduduk Indonesia (BNN RI, 2015).

Tingginya angka prevalensi tersebut tentunya memerlukan penanganan segera agar tidak semakin meningkat salah satunya diterbitkannya Peraturan Pemerintah Nomor 25 Tahun 2011 tentang pelaksanaan wajib lapor serta peraturan bersama Mahkumjakpol-Kemenkes-Kemensos-BNN tahun 2014 tentang penanganan pecandu narkotika dan korban penyalahgunaan narkotika ke dalam lembaga rehabilitasi dan rehabilitasi lanjutan (Pascarehabilitasi). Implementasi dari kedua peraturan tersebut tentu berimplikasi pada ketersediaan lembaga rehabilitasi dan pascarehabilitasi yang memadai dan sesuai dengan kebutuhan korban penyalah guna dan pecandu narkotika (BNN RI, 2015).

Peran rehabilitasi dalam penanggulangan penyalahgunaan narkoba sangat penting, karena setiap tahun slalu ada penyalahgunaan Narkoba tingkat Nasional maupun tingkat lokal di Maluku Utara. Hal ini sebagaimana data BNNP Maluku Utara pada tabel 1 di bawah ini :

Tabel 1. Jumlah Kasus dan Jenis Penyalahgunaan Narkoba yang Telah Direhabilitasi Oleh BNN Provinsi Maluku Utara Tahun 2016-2019

\begin{tabular}{ccccc}
\hline & \multicolumn{3}{c}{ Jenis Penyalahgunaan Narkoba } & \multirow{2}{*}{ Total } \\
\cline { 2 - 5 } Tahun & Ganza & Sabu & Inhalan & $\mathbf{6 1}$ \\
\hline $\mathbf{2 0 1 6}$ & 36 & 25 & - & $\mathbf{3 2}$ \\
\hline $\mathbf{2 0 1 7}$ & 7 & 25 & - & $\mathbf{3 7}$ \\
\hline $\mathbf{2 0 1 8}$ & 20 & 10 & 7 & $\mathbf{8}$ \\
\hline $\mathbf{2 0 1 9}$ & 2 & 3 & 3 & \\
\hline
\end{tabular}

Sumber: BNNP Maluku Utara 2016-2019

Berdasarkan Tabel 1, dapat diketahui pada tahun 2016 terdapat jumlah kasus penyalahgunaan narkoba sebanyak 61 orang dengan jenis narkoba ganja dan sabu, dan pada tahun 2017 ditemukan pula pengguna ganza sebanyak 7 kasus dan pengguna sabu sebanyak 25 kasus jadi total penyalahgunaan narkoba pada tahun 2017 sebanyak 32 orang. Sedangkan pada tahun 2018 dan 2019 ditemukan jenis pengguna narkoba baru yakni inhalan. Dan Seluruh penyalahguna narkoba telah medapatkan pelayanan rehabilitasi oleh Badan Narkotika Nasional Provinsi Maluku Utara.

Dalam menanggulangi penyalahgunaan narkoba dan rehabilitasi pengguna narkoba, maka diperlukan langkah strategik yang dikenal dengan Strategi Promosi Kesehatan. Strategi ini meliputi kegiatan Advokasi, Kemitraan dan Pemberdayaan Masyarakat. Advokasi (Advocacy) yaitu kegiatan yang ditujukan kepada pembuat keputusan atau penentu kebijakan baik di bidang kesehatan maupun sektor lain di luar kesehatan yang mempunyai pengaruh terhadap publik agar para pembuat keputusan mengeluarkan kebijakan-kebijakan yang menguntungkan kesehatan publik (Notoatmodjo, 2010). Menurut Notoatmodjo (2003), kemitraan adalah suatu kerja sama formal antara individu 
individu, kelompok-kelompok atau organisasi-organisasi untuk mencapai suatu tugas atau tujuan tertentu. dan Pemberdayaan masyarakat dalam bidang kesehatan lebih kepada untuk meningkatkan partisipasi masyarakat dalam bidang kesehatan. Partisipasi masyarakat adalah kegiatan pelibatan masyarakat dalam suatu program. Diharapkan dengan tingginya partisipasi dari masyarakat maka suatu program kesehatan dapat lebih tepat sasaran dan memiliki daya ungkit yang lebih besar bagi perubahan perilaku karena dapat menimbulkan suatu nilai di dalam masyarakat bahwa kegiatankegiatan kesehatan tersebut itu dari kita dan untuk kita (Notoatmodjo, 2010).

Berdasarkan hasil penelitian yang dilakukan oleh Rama Nur Kurniawan. K (2018) dengan judul: Strategi Promosi Kesehatan Terhadap Upaya Penanggulangan Penyalahgunaan Narkoba di Dinas Kesehatan Kabupaten Wajo, hasil penelitian menunjukkan bahwa: (1) Advokasi yang dilakukan Dinas Kesehatan Kabupaten Wajo dengan cara mengusulkan bantuan dana kepada Pemerintah Daerah, untuk keperluan kegiatan penyuluhan napza di sekolah. (2) Kemitraan yang dilakukan Dinas Kesehatan terhadap upaya penanggulangan narkoba dengan membangun kerjasama dengan pihak polres, sekolah, puskesmas dan pemda. Dan (3) Pemberdayaan yang dilakukan dinas kesehatan dan puskesmas, dengan membentuk kader kesehatan remaja di sekolah sebagai bentuk keikutsertaan siswa dalam memberantas narkoba di Kabupaten Wajo.

Menurut pasal 70 huruf d Undang-Undang 35 tahun 2009 tentang narkotika, Badan Narkotika Nasional memiliki tugas meningkatkan kemampuan lembaga rehabilitasi medis dan rehabilitasi sosial pecandu narkotika, baik yang diselenggarakan oleh pemerintah maupun oleh masyarakat (UU Narkotika 2009) Peningkatan kemampuan dilakukan antara lain melalui pemberian penguatan, dorongan, atau fasilitasi kepada lembaga rehabiltasi medis dan rehabilitasi sosial yang diselenggarakan oleh pemerintah maupun oleh masyarakat. Secara vertikal, BNN didukung oleh BNN tingkat Provinsi dan BNN Kabupaten/Kota agar peneyelenggaraan rehabilitasi medis dan rehabilitasi sosial dapat berjalan dengan baik.

\subsection{Tujuan dan Manfaat Penelitian}

Tujuan Umum dari penelitian ini adalah untuk mengetahui Strategi Promosi Kesehatan dalam upaya rehabilitasi penyalahgunaan narkoba oleh Badan Narkotika Nasional Provinsi Maluku Utara. Dan Tujuan Khusus yaitu : (a) untuk mengetahui Advokasi BNNP Maluku Utara dalam upaya rehabilitasi penyalahgunaan narkoba, (b) Untuk mengetahui bentuk Kemitraan BNNP Maluku Utara dalam upaya rehabilitasi penyalahgunaan narkoba, (c) Untuk Mengetahui bagaimanakah Pemberdayaan Masyarakat yang dilakukan oleh BNNP Malut dalam upaya rehabilitasi penyalahgunaan narkoba.

Manfaat dalam Penelitian ini yaitu (1) Manfaat bagi Institusi adalah dapat menjadi bahan informasi dan rekomendasi bagi BNNP Malku Utara dalam melakukan upaya rehabilitasi penyalahguna narkotika, (2) Manfaat bagi Peneliti adalah merupakan pengalaman bagi peneliti dalam mengaplikasikan ilmu dan menambah wawasan mengenai upaya rehabilitasi bagi penyalahgunaan narkoba di BNNP Maluku Utara, (3) Manfaat bagi Ilmu Pengetahuan yaitu dapat menambah khasanah ilmu pengetahuan dan dapat menjadi bahan referensi bagi penelitian selanjutnya.

\section{METODE PENELITIAN}

Jenis penelitian yang digunakan adalah penelitian kualitatif dengan Teknik dasar penelitian ini adalah wawancara mendalam dengan informan dan hal ini juga dikemukakan oleh Meleong (2007) adalah penelitian yang bermaksud untuk memahami fenomena tentang apa yang dialami oleh subjek penelitian misalnya perilaku, persepsi, motivasi, tindakan, dll., secara holistik, dan dengan cara deskripsi dalam bentuk kata-kata dan bahasa, pada suatu konteks khusus yang alamiah dan dengan memanfaatkan berbagai metode alamiah yang bertujuan untuk memperoleh informasi tentang pelaksanaan strategi promosi kesehatan dalam upaya rehabilitasi penyalahgunaan Narkoba.

\subsection{Waktu dan Lokasi Penelitian}

Penelitian telah dilaksanakan pada Tanggal 12 - 17 September 2019 di Kota Ternate, Lokasi penelitian di kantor Badan Narkotika Nasional Provinsi (BNNP) Mauku Utara dan Lapas Kelas IIA Ternate. 


\subsection{Informan Penelitian}

Informan dalam penelitian ini berjumlah 4 orang, yang terdiri dari 2 orang informan kunci dan 2 orang informan pendukung yaitu : (1) Kepala Bidang Rehabiltasi BNNP Maluku Utara (Informan Kunci), (2) Asesor BNN Provinsi Maluku Utara (Informan Pendukung), (3) Kepala Bidang Binaan Napi dan Anak Lapas Kelas IIA Ternate (Informan Kunci), (4) Asesor Lapas Kelas IIA Ternate Bagian Binadik (Informan Pendukung)

\subsection{Pengumpulan Data}

Pengumpulan data dalam penelitian ini terdiri dari data primer dan data skunder. Data primer adalah adalah data yang diperoleh langsung dari subjek penelitian dengan mengenakan pengambilan data. Sedangkan data sekunder adalah data yang diperoleh lewat pihak lain, tidak diperoleh peneliti dari subjek penelitiannya (Saryono, 2008).

Data primer diperoleh melalui wawancara langsung dengan 4 orang informan yaitu: Kepala Bidang Rehabiltasi BNNP Maluku Utara, Asesor BNNP Malut, Kepala Bidang Binaan Napi dan Anak Lapas Klas IIA Ternate dan Asesor Lapas Klas IIA Ternate. Dan data sekunder diperoleh dari Profil Badan Narkotika Nasional Propinsi Maluku Utara serta Reverensi dari buku-buku cetak.

\subsection{Pengolahan dan Analisis Data}

Analisis data kualitatif adalah proses mencari dan menyusun data secara sistemetis data yang diperoleh dari hasil wawancara, catatan lapangan, dan bahan-bahan lain sehingga dapat mudah difahami, dan temuannya dapat diinformasikan kepada orang lain (Sugiyono, 2018).

a. Reduksi data

Adalah proses merangkum, memilih hal-hal yang pokok, memfokuskan pada hal-hal yang penting dan mengorganisasikan data sehingga akhirnya dapat ditarik kesimpulan.

b. Display data/ penyajian data

Penyajian data bisa dilakukan dalam bentuk uraian singkat, bagan, hubungan antara kategori mengenai apa yang di lihat dan didengar baik secara langsung maupun dari hasil rekaman.

c. Conclusion drawing/verification

Kesimpulan awal dalam penelitian kualitatif masih bersifat sementara dan akan berubah bila terdapat bukti-bukti baru. Namun jika kesimpulan pada tahap awal mendukung oleh bukti-bukti yang valid dan konsisten saat penelitian kembali ke lapangan maka kesimpulan tersebut kesimpulan yang kredibel (Shohibuka, 2009)

\subsection{Penyajian Data}

Penyajian data dilakukan dengan cara mengelompokan hasil wawancara, kemudian diinterpretasikan dan di sajikan dalam bentuk narasi (Moleong, 2007).

\section{HASIL DAN PEMBAHASAN}

Penelitin ini telah dilakukan di Badan Narkotika Nasional Provinsi (BNNP) Maluku Utara dan Lembaga Pemasyarakatan (Lapas) Kelas IIA Ternate pada tanggal 12-17 September 2019. Informan yang diwawancarai dalam penelitian sebanyak 4 orang, yaitu : (1) Kepala Bidang Rehabilitasi BNNP Maluku Utara sebagai Informan Kunci, (2) Asesor BNNP Malut selaku informan Pendukung, (3) Kepala Bidang Binaan Napi dan Anak Lapas Kelas IIA Ternate sebagai informan Kunci, dan (4) Asesor Lapas Kelas IIA Ternate (Bagian Binadik) selaku informan Pendukung. Adapun pendidikan informan S2 Publik Health, S1 Kesehatan Masyarakat, S1 Hukum dan D3 Kebidanan. Dan umur informan 34, 47, 50 dan 52 Tahun. Serta berdasarkan jenis kelamin, laki-laki sebanyak 2 orang dan perempuan juga sebanyak 2 orang.

Penelitian ini dilakukan untuk memperoleh informasi secara mendalam mengenai Advokasi, Kemitraan dan Pemberdayaan dalam upaya rehabilitasi penyalahgunaan narkoba di BNN Provinsi Maluku Utara. Hasil dari ke tiga variabel penelitian tentang upaya rehabilitasi penyalahgunaan narkoba dapat di lihat dibawah ini : 


\subsection{Advokasi}

Tabel 2. Pihak yang terlibat dalam upaya rehabilitasi penyalahgunaan Narkoba

\begin{tabular}{|c|c|c|}
\hline No & $\begin{array}{c}\text { Kode } \\
\text { Informan }\end{array}$ & Jawaban Informan \\
\hline 1 & JS & $\begin{array}{l}\text { "Kita memperoleh dukungan dari berbagai pihak baik pemerintah maupun masyarakat } \\
\text { diantaranya : RSUD Dr. Chasan Boesoirie, RS Bhayangkara, Klinik Pratama BNNP, Klinik } \\
\text { Biddokes Polda Malut, Puskesmas Kalumata, RSD Kota Tikep, Lapas Kelas IIA Ternate, LSM } \\
\text { dan lain-lain" }\end{array}$ \\
\hline 2 & SU & $\begin{array}{l}\text { "Institusi pemerintah dan Komponen Masyarakat, yaitu: Puskesmas Kalumata, Bapas dan } \\
\text { Lapas Kelas IIA Ternate, Rumah Sakit Umum Ternate, LSM Rorano, dan lain-lain" }\end{array}$ \\
\hline 3 & MR & "Salah satu pihak yang terlibat dalam upaya rehabilitasi yaitu BNN Provinsi Malut" \\
\hline 4 & WM & "Pihak yang terlibat dalam rehabilitasi adalah BNNP Malut" \\
\hline
\end{tabular}

Interpretasi : Berdasarkan jawaban dari ke-4 informan ada beberapa instansi pemerintah yang mendukung BNNP Maluku Utara dalam upaya rehabilitasi penyalahgunaan narkoba, yaitu institusi pemerintah; RSUD Dr. Chasan Boesoirie, RS Bhayangkara, Klinik Pratama BNNP, Klinik Biddokes Polda Malut, Puskesmas Kalumata, RSD Kota Tikep, Bapas dan Lapas Kelas IIA Ternate dan Komponen Masyarakat: LSM Rorano dan lain-lain.

Dan berdasarkan data sekunder Bidang Rehabilitasi BNNP Maluku Utara Tahun 2018, selaian instansi yang telah disebutkan di atas ada pula BNNP Maluku Utara telah berkerja sama degan instansi lain yaitu : Institusi Pemerintah (IP) yaitu : RSUD Sanana Kab. Kepulauan Sula, RSUD Labuha Kab. Halmahera Selatan, RSUD Maba Kab. Halmahera Timur, Puskesmas Perawatan Obi, RSUD Halmahera Barat, dan RSUD Halmahera Tengah. Adapula dukungan dari Komponen Masyarakat (KM) yaitu : Klinik Annelevi, LSM Pena, LSM Cengkih Institute, dan LSM Mahuhahide.

Tabel 3. Kegiatan advokasi yang dilakukan dalam upaya rehabilitasi penyalhgunaan Narkoba

\begin{tabular}{|c|c|c|}
\hline No & $\begin{array}{c}\text { Kode } \\
\text { Informan }\end{array}$ & Jawaban Informan \\
\hline 1 & JS & $\begin{array}{l}\text { "kegiatan advokasi yaitu melakukan Peningkatan kompetensi, bimtek, sosialisasi, asistensi } \\
\text { pada instansi terkait untuk layanan program rehabilitasi" }\end{array}$ \\
\hline 2 & SU & $\begin{array}{l}\text { "Membina raport dengan klien dan keluarga. Melakukan koumunikasi dengan tenaga } \\
\text { profesioanal baik Institusi pemerintah dan Komponen Masyarakat" }\end{array}$ \\
\hline 3 & MR & $\begin{array}{l}\text { "Kegiatan advokasi yang dilakukan oleh BNN Malut dan Lapas terkait rehabilitasi dan } \\
\text { pascarehabilitasi untuk penyalahguna narkoba melalui bimtek, asisten, sosialisasi" }\end{array}$ \\
\hline 4 & WM & "Bimtek layanan program rehabilitasi dan pascarehabilitasi" \\
\hline
\end{tabular}

Interpretasi : berdasarkan hasil wawancara dengan ke-4 informan kunci maupun informan pendukung dapat diketahui Kegiatan-kegiatan advokasi dalam upaya rehabilitasi penyalahgunaan narkoba yaitu :

1. Melakukan kegiatan kompetensi, adalah di mana Lembaga-lembaga yang belum melakukan layanan rehabilitasi dari BNN melakukan peningkatan kompetensi di Lembaga Institusi Pemerintah (IP) dan komponen masyarakat, agar Lembaga itu dapat mandiri untuk melakukan layanan rehabilitasi antara lain; skrining, assessment dan konseling.

2. Bimtek : kegiatan bimbingan teknis ini dilakukan oleh BNN Pusat maupun BNNP, tujuan bimtek ini diselenggarakan agar terciptanya penyamaan pelaksanaan program dari pusat sampai ke daerah sebagai wadah dalam bertukar informasi. Perihal persiapan kegiatan peningkatan kemampuan.

3. Sosialisasi, dilakukan untuk lebih memperkenalkan layanan rehabilitasi dan untuk memaksimal mengingat rendahnya angka kunjungan melalui humas dan media cetak.

4. Membina raport dengan klien dan keluarga pengguna : untuk mencari tahu sejaumana klien melakukan perubahan atas dirinya baik aktifitas dan tingkat penggunaan zat, sedangkan keluarga untuk mengetahui sejauhmana dukungan motivasi, perhatian keluarga kepada klien dan melakukan pengawasan saat klien beraktifitas di rumah.

5. Melakukan koumunikasi dengan tenaga profesioanal, maksudnya jika ada klien yang mempunyai riwayat diagnose tambahan dari BNNP jalin komunikasi/konsultasi dengan tenaga professional antara lain dokter dan psikolog, misalnya ada kecenderungan klien dengan psikis. 
Tabel 4. Dukungan-dukungan yang telah dilakukan oleh lintas program maupun lintas sektor dalam upaya rehabilitasi penyalahgunaan Narkoba

\begin{tabular}{|c|c|c|}
\hline No & $\begin{array}{c}\text { Kode } \\
\text { Informan }\end{array}$ & Jawaban Informan \\
\hline 1 & JS & $\begin{array}{l}\text { "Melakukan rapat kordinasi antar pemangku kepentingan, bimtek, monitoring dan } \\
\text { evaluasi. Dukungan yang dilakukan peningkatan kompetensi petugas di IP dan KM dalam } \\
\text { layanan program rehabilitasi setelah itu lembaga tesbut melakukan layanan rehabilitasi di } \\
\text { lembaga tersebut" }\end{array}$ \\
\hline 2 & SU & $\begin{array}{l}\text { "Sinergitas layanan rehabilitasi rawat jalan berkelanjutan. Layanan rawat jalan IP dan KM } \\
\text { Pencatatan dan Pelaporan" }\end{array}$ \\
\hline 3 & MR & $\begin{array}{l}\text { "Memberikan edukasi terhadap bakat yang di miliki oleh warga binaan dari instansi } \\
\text { terkait dengan dukungan dalam bentuk PKS dan MOU antara lain : (1) BNN, (2) Disnaker, } \\
\text { (3) Dinkes dan lain-lain" }\end{array}$ \\
\hline 4 & WM & "Assessment Bakat dan minat klien, dan penyakit menyertai" \\
\hline
\end{tabular}

Berdasarkan hasil wawancara dapat diketahui bahwa telah dilakukannya upaya-upaya rehabilitasi penyalhgunaan narkoba oleh pihak BNNP Malut dan Lapas Kelas IIA Ternate yaitu (1) Melakukan rapat kordinasi antar pemangku kepentingan, bimtek, pemetaan, monitoring dan evaluasi. (2) Melakukan upaya-upaya Peningkatan kompetensi petugas di Institusi Pemerintah (IP) dan Komponen Masyarakat (KM) dalam layanan program rehabilitasi. (3) Telah memberikan edukasi terhadap warga binaan (penyalah guna) dari pihak BNNP Malut, Dinas tenaga kerja (Disnaker), dan Dinkes Kota Ternate

Tabel 5. Proses dalam pelaksanaan kegiatan advokasi

\begin{tabular}{ccl}
\hline No & $\begin{array}{c}\text { Kode } \\
\text { Informan }\end{array}$ & \multicolumn{1}{c}{ Jawaban Informan } \\
\hline 1 & JS & $\begin{array}{l}\text { "Prosesnya melalui rapat koordinasi oleh lintas terkait, layanan program yang telah } \\
\text { dilakukan oleh lembaga terkait" } \\
\text { "Melakukan mediasi, kolaborasi, penyebaran leaflet dan selebaran" } \\
\text { "Sangat Baik dalam pelaksanan program layanan rehabilitasi, Sama-sama dalam } \\
\text { melakukan pemantauan dan pengawasan dalam melakukan layanan rehabilitasi dan } \\
\text { pascarehabilitasi untuk warga binaan" }\end{array}$ \\
& $\mathrm{SU}$ & "Prosesnya berjalan dengan baik dalam pelaksanaan program rehabilitasi" \\
\hline
\end{tabular}

Berdasarkan hasil wawancara dengan informan terkait Proses pelaksanaan kegiatan advokasi yaitu : (1) Melalui rapat koordinasi oleh lintas terkait, (2) Memberikan layanan program rehabilitasi, (3) Melakukan mediasi, kolaborasi, penyebaran leaflet dan selebaran, (4) Melakukan pemantauan dan pengawasan dalam layanan rehabilitasi dan pascarehabilitasi pada warga binaan, (5) Prosesnya berjalan dengan baik dalam pelaksanaan program rehabilitasi.

Tabel 6. Output dalam pelaksanaan advokasi terkait masalah rehabilitasi

\begin{tabular}{|c|c|c|}
\hline No & $\begin{array}{c}\text { Kode } \\
\text { Informan }\end{array}$ & Jawaban Informan \\
\hline 1 & JS & $\begin{array}{l}\text { "Outputnya; rapat koordinasi terlaksana tetapi dampak dari rakor sebagian sudah } \\
\text { terlaksana dan sebagian belum terlaksana yang terlaksana antara lain dari } \\
\text { lembaga tersebut telah membuat layanan. Instansi yang sudah melaksanakan } \\
\text { yaitu; Dinkes Kota Ternate, Polda Malut dan jajarannya, Lapas Kelas IIA Kota } \\
\text { Ternate, Hukum dan HAM serta jajarannya, Pengadilan, LSM dan Klinik Swasta" }\end{array}$ \\
\hline 2 & SU & $\begin{array}{l}\text { "Klien bersedia di Assesment, Orang tua/keluarga bersedia mendampingi dan } \\
\text { memotivasi klien, serta Jumlah layanan meningkat" }\end{array}$ \\
\hline 3 & MR & $\begin{array}{l}\text { "Sudah melakukan kerjasama dengan BNN dan institusi lainya terkait rehabilitasi } \\
\text { dan lainnya" }\end{array}$ \\
\hline 4 & WM & $\begin{array}{l}\text { "Adanya dukungan kerjasama yang baik antar BBNP Malut dengan Lapas terkait } \\
\text { masalah rehabilitasi" }\end{array}$ \\
\hline
\end{tabular}


Output pelaksanan Advokasi dalam upaya rehabilitasi yaitu :

1. Melakukan rapat koordinasi, terlaksana tetapi dampak dari rakor sebagian sudah terlaksana dan sebagian belum terlaksana

2. Ada Lembaga atau instansi yang telah melakukan proses pelayanan rehabilitasi yaitu; BNNP Malut, Dinkes Kota Ternate, Polda Malut, Lapas Kelas IIA Kota Ternate, Lembaga Hukum dan HAM, Pengadilan, LSM dan Klinik Swasta

3. Klien bersedia di Assesment, Orang tua/keluarga bersedia mendampingi dan memotivasi klien Adanya dukungan kerjasama yang baik antar BBNP Malut dengan Lapas terkait masalah rehabilitas.

\subsection{Kemitraan}

Tabel 7. Kemitraan yang telah dilakukan dalam upaya rehabilitasi penyalhguna Narkoba

\begin{tabular}{|c|c|c|}
\hline No & $\begin{array}{c}\text { Kode } \\
\text { Informan }\end{array}$ & Jawaban Informan \\
\hline 1 & JS & $\begin{array}{l}\text { "Dalam hubungan kemitraan sudah melakukan PKS dan MoU untuk melakukan layanan } \\
\text { upaya rehabilitasi narkoba di IP dan KM" }\end{array}$ \\
\hline 2 & SU & $\begin{array}{l}\text { "Layanan rehabilitasi medis dan sosial baik di institusi pemerintah dan komponen } \\
\text { masyarakat" }\end{array}$ \\
\hline 3 & MR & "PKS Dan MoU dengan BNNP Malut" \\
\hline 4 & WM & "Melakukan MoU dan Perjanjian Kerjasama dengan BNNP" \\
\hline
\end{tabular}

Berdasarkan hasil wawancara dengan informan JS, SU, MR dan WM Kemitraan atau Kerjasama dalam upaya rehabilitasi penyalhgunaan narkoba yaitu :

1. Membuat Perjanjian Kerja Sama (PKS)

2. MoU dengan Institusi Pemerintah (IP)

3. MoU dengan Komponen Masyarakat (KM)

4. Isi dari Kerjasama yaitu Memberikan Layanan rehabilitasi medis, sosial dan pascarehabilitasi

Tabel 8. Bentuk kerjasama dengan lintas sektor dalam upaya rehabiltasi penyalahgunaan Narkoba

\begin{tabular}{|c|c|c|}
\hline No & $\begin{array}{c}\text { Kode } \\
\text { Informan }\end{array}$ & Jawaban Informan \\
\hline 1 & JS & "Bentuk kerja sama pelatihan petugas, dukungan layanan dan penyediaan anggaran" \\
\hline 2 & SU & $\begin{array}{l}\text { "Layanan rehabilitasi medis dan sosial baik di institusi pemerintah dan komponen } \\
\text { masyarakat" }\end{array}$ \\
\hline 3 & MR & "Layanan program rehabilitasi dan pascarehabilitasi" \\
\hline 4 & WM & "Memberikan pelayanan rehabilitasi dan pascarehabilitasi" \\
\hline
\end{tabular}

Berdasarkan hasil wawancara langsung dengan ke-4 informan, maka dapat diketahui bentuk kerjasama dengan lintas sektor dalam upaya rehabiltasi penyalahgunaan narkoba yaitu : (1) Pelatihan petugas, (2) Layanan program rehabilitasi medis, sosial, dan program pascarehabilitasi, dan (3) Penyediaan anggaran.

Tabel 9. Bentuk kerjasama dengan lintas program dalam upaya rehabiltasi penyalahgunaan Narkoba

\begin{tabular}{|c|c|c|}
\hline No & $\begin{array}{c}\text { Kode } \\
\text { Informan }\end{array}$ & Jawaban Informan \\
\hline 1 & JS & $\begin{array}{l}\text { "Kerja sama lintas program internal membangun sinergitas antar bidang antara lain : } \\
\text { penyuluhan, pemberdayaan pada mantan pengguna tetapi kegiatan ini belum optimal } \\
\text { sehingga semua sasaran belum tercover. Dan untuk pelaksanaan rehabiliatsi kasus apabila } \\
\text { terkait hukum jika ditemukan urine positf namun tdk ditemukan barang bukti maka dari } \\
\text { bidang brantas menyerahkan klien untuk dilakukan rehabilitasi" }\end{array}$ \\
\hline 2 & SU & $\begin{array}{l}\text { "Membuat group wa sebagai fasilitas untuk koordinasi dengan layanan program } \\
\text { rehabilitasi" }\end{array}$ \\
\hline 3 & MR & "Melalui sosialisasi program layanan rehabilitasi dengan lintas program" \\
\hline 4 & WM & "melakukan koordinasi dengan Kabid Binaan Napi dan Anak" \\
\hline
\end{tabular}

Malalui wawancara dengan ke-4 informan, maka dapat diketahui Bentuk kerjasama lintas program dalam upaya rehabiltasi penyalahgunaan narkoba yaitu : 
1. Adanya kerja sama lintas program membangun sinergitas antar bidang dengan melakukan kegiatan penyuluhan, pemberdayaan pada mantan pengguna: sinergitas layanan baik oleh bidang P2M, Berantas dan bidang rehabilitasi.

2. Dalam pelaksanaan rehabiliatsi kasus apabila terkait hukum jika ditemukan urine positf namun tidak ditemukan barang bukti maka dari bidang Brantas menyerahkan klien untuk dilakukan rehabilitasi.

3. Membuat group WA sebagai fasilitas untuk koordinasi dengan layanan program rehabilitasi.

4. Melakukan koordinasi dan sosialisasi terkait program rehabilitasi secara internal (lintas program)

Tabel 10. Hasil (output) dari kerjasama antara lintas program maupun lintas sektor dalam upaya pelayanan rehabilitasi pengguna Narkoba

\begin{tabular}{ccc}
\hline No & $\begin{array}{c}\text { Kode } \\
\text { Informan }\end{array}$ & Jawaban Informan \\
\hline 1 & JS & "Outputnya terlaksaananya program rawatjalan dan rawatinap" \\
2 & SU & "Menjadwalkan pertemuan secara rutin" \\
3 & MR & $\begin{array}{l}\text { "Warga binaan merasakan hasil dari pelaksanaan program rehabilitasi dan } \\
\text { pascarehabilitasi dapat menambah pengetahuan dan ada perubahan sikap dan perilaku" }\end{array}$ \\
4 & WM & $\begin{array}{c}\text { "Warga binaan merasakan hasil dari kegiatan rehabilitasi dan pascarehabilitasi dapat } \\
\text { meningkatkan pengetahuan dan adanya perubahan perilaku" }\end{array}$ \\
\hline
\end{tabular}

Dari informasi yag diberikan oleh informan dari pihak BNN Provinsi Maluku Utara yaitu JS dan SU dan informasi yang diberikan oleh informan dari Lembaga Pemasyarakatan (Lapas) Kelas IIA Ternate Hasil (output) dari kerjasama antara lintas program maupun lintas sektor dalam upaya pelayanan rehabilitasi pengguna narkoba adalah :

1. Terlaksaananya program rawat jalan dan rawat inap

2. Terjadwanya pertemuan secara rutin

3. Warga binaan/pegguna dan mantan penyalhgunaan narkoba merasakan Hasil dari pelaksanaan program rehabilitasi dan pascarehabilitasi dapat menambah pengetahuan dan ada perubahan sikap dan perilaku

\subsection{Pemberdayaan}

Tabel 11. Kegiatan pemberdayaan masyarakat yang dilakukan dalam upaya rehabilitasi penyalhgunaan Narkoba

\begin{tabular}{ccl}
\hline No & $\begin{array}{c}\text { Kode } \\
\text { Informan }\end{array}$ & \multicolumn{1}{c}{ Jawaban Informan } \\
\hline 1 & JS & $\begin{array}{l}\text { "Untuk pemberdayaan bidang P2M melakukan pelatihan kade dan pascarehabilitasi } \\
\text { memberikan klien untuk melakukan vocasional ketrampilan khusus kerja sama dengan } \\
\text { BLK dan Dinsos" } \\
\text { "Memotivasi klien agar mengikuti program rehabilitasi dan mendorong klien untuk } \\
\text { mengasah ketrampilan dirinya" }\end{array}$ \\
3 & $\mathrm{SU}$ & $\begin{array}{l}\text { "Warga binaan skilnya dapat bekerja di bengkel, di Dinas Pertanian dan lain-lain, sesuai } \\
\text { ketrampilan yang didapat selama menjalani pembinaan di lapas" }\end{array}$ \\
4 & $\mathrm{WM}$ & $\begin{array}{l}\text { "Memberikan peluang bagi Warga binaan untuk mengembangkan skilnya atau } \\
\text { ketrampilan kerja seperti kerja bengkel dan pertanian" }\end{array}$ \\
\hline
\end{tabular}

Berdasarkan hasil penelitian dapat diketahui Kegiatan-kegiatan pemberdayaan pada klien atau penyalahgunaan narkoba yaitu :

1. Pascarehabilitasi memberikan klien melakukan vocasional ketrampilan khusus kerja sama dengan Balai Latihan Kerja (BLK) dan Dinas sosial (Dinsos)

2. Memotivasi klien agar mengikuti program rehabilitasi

3. Mendorong klien untuk mengasah ketrampilan dirinya seperti bekerja di bengkel dan pertanian selama menjalani pembinaan di lapas 
Tabel 12. Kendala apa yang dihadapi dalam pelaksanaan kegiatan rehabiltasi penyalahgunaan Narkoba

\begin{tabular}{ccl}
\hline No & $\begin{array}{c}\text { Kode } \\
\text { Informan }\end{array}$ & \multicolumn{1}{c}{ Jawaban Informan } \\
\hline 1 & JS & $\begin{array}{l}\text { "keterbatasan sarana prasarana untuk mengembangkan bakat klien (rumah damping), } \\
\text { Kurangnya pengguna yang lapor diri secara sukarela, belum ada Lembaga rehabilitasi } \\
\text { Rawat inap di Maluku Utara" } \\
\text { "Bakat klien tidak terpenuhi karena belum ada rumah damping di BNNP itu sendiri dan } \\
\text { kemampuan sumber daya yang terbatas" }\end{array}$ \\
3 & $\mathrm{SU}$ & $\begin{array}{l}\text { "Tidak ada kendala" } \\
\text { "Kendala sih tidak ada" }\end{array}$ \\
\hline
\end{tabular}

Berdasarkan hasil wawancara dengan ke-empat informan, ada 2 informan dari BBNP Malut yang ber inisial JS dan SU mengatakan bahwa ada Kendala yang dihadapi dalam pelaksanaan kegiatan Rehabilitasi dan pascarehabilitasi yaitu :

1. Keterbatasan sarana prasarana untuk mengembangkan bakat klien (rumah damping)

2. Kurangnya pengguna yang lapor diri secara sukarela

3. Sumber daya yang terbatas

4. Belum ada Lembaga rehabilitasi Rawat inap di Maluku Utara

Tabel 13. Penyuluhan dan pelatihan yang telah dilakukan dalam upaya pemberdayaan pengguna Narkoba

\begin{tabular}{ccl}
\hline No & $\begin{array}{c}\text { Kode } \\
\text { Informan }\end{array}$ & Jawaban Informan \\
\hline 1 & JS & $\begin{array}{l}\text { "Lintas program sudah melaksanakan pelatihan dan penyuluhan untuk klien terkait } \\
\text { ketrampilan yang di miliki selain itu memberikan informasi tentang layanan program } \\
\text { rehabilitasi dan dampak dari narkoba untuk para pengguna" }\end{array}$ \\
& "Ada tetapi kegiatan itu melekat di bidang P2M tentang pemberdayaan di bidang \\
2 & SU & $\begin{array}{l}\text { rehabiliatasi kami bekerja sama dengan BLKatau Dinsos" } \\
\text { "Ada, yang di lakukan dari Dinsos, Puskesmas, BNN" } \\
\text { Ada penyuluhan dilakukan oleh Puskesmas dan BNN Provinsi dan ada pelatihan yang } \\
\text { diberikan oleh Dinas Sosial" }\end{array}$ \\
\hline
\end{tabular}

Interpratasi: berdasarkan hasil wawancara dengan informan JS, SU, MR dan WM upaya pemberdayaan pengguna narkoba dengan melakukan penyuluhan dan pelatihan yaitu :

1. Telah melaksankan penyuluhan dalam memberikan informasi tentang layanan program rehabilitasi dengan tujuan agar klien mau dan terus melakukan rehabilitasi di Klinik Pratama BNNP malut,

2. Telah memberikan penyuluham tentang dampak dari narkoba oleh BNNP, Puskesmas dan Dinas kesehatan dengan tujun agar pengguna dapat mengetahui bahaya penggunaan narkoba

3. Telah Melaksanakan pelatihan buat klien terkait ketrampilan yang di miliki sesuai bakat dan minat melalui BLK dan Dinas Sosial

Tabel 14. Pengawasan kegiatan pemberdayaan pada Klien yang direhabilitasi

\begin{tabular}{|c|c|c|}
\hline No & $\begin{array}{c}\text { Kode } \\
\text { Informan }\end{array}$ & Jawaban Informan \\
\hline 1 & JS & "Untuk pengawasan dalam pemberdayaan dilakukan melalui monitoring dan evaluasi" \\
\hline 2 & SU & "Pendampingan klien, Komunikasi dengan org tua dan keluarga dekat" \\
\hline 3 & MR & $\begin{array}{l}\text { "Selama dalam masa binaan warga, binaan selalu di awasi dan pantau melalui petugas } \\
\text { Lapas dgn izin tertulis melalui Cuti Bersyarat (CB), Jika pemberdayaan dilakukan di luar } \\
\text { Lapas" }\end{array}$ \\
\hline 4 & WM & "Warga binaan yang direhabilitasi selalu di awasi dan pantau oleh petugas Lapas" \\
\hline
\end{tabular}

Interpratasi, Pengawasan kegiatan pemberdayaan pada Klien yang direhabilitasi yaitu :

1. Melalui monitoring dan evaluasi

2. Pendampingan klien

3. Komunikasi dengan org tua dan keluarga dekat

4. Warga binaan selalu di awasi dan pantau melalui petugas Lapas

5. Jika pemberdayaan dilakukan di luar Lapas, maka ada izin tertulis melalui Cuti Bersyarat (CB) 
Tabel 15. Keberhasilan kegiatan pemberdayaan dalam upaya rehabilitasi penyalahgunaan Narkoba

\begin{tabular}{|c|c|c|}
\hline No & $\begin{array}{l}\text { Kode } \\
\text { Informan }\end{array}$ & Jawaban Informan \\
\hline 1 & JS & $\begin{array}{l}\text { "Keberhasilan tiga tahun terakhir klien pulih produktif sudah ada pekerjaan tetap setelah } \\
\text { kembali ke fungsi sosial, pulih tdk produktif karena belum ada pekerjaan tetap" }\end{array}$ \\
\hline 2 & SU & "Adanya kasus voulantary yang meningkat" \\
\hline 3 & MR & $\begin{array}{l}\text { "Semua warga binaan sudah diberdayakan Melalui pascarehabilitasi dengan kegiatan } \\
\text { vokasional yang kerja sama dengan Dinas Sosial dan BLK" }\end{array}$ \\
\hline 4 & WM & $\begin{array}{l}\text { "keberhasilannya selesai direhabilitasi yakni warga binaan diberikan juga program } \\
\text { pascarehabilitasi, sehingga mereka dapat mengapikasikan Bakat dan minat di tempat } \\
\text { warga binaan bekerja" }\end{array}$ \\
\hline
\end{tabular}

Berdasarkan hasil penelitian diketahui ada 5 Keberhasilan kegiatan pemberdayaan dalam upaya rehabilitasi penyalahgunaan narkoba yaitu :

1. Klien pulih produktif

2. Sudah ada pekerjaan tetap setelah kembali ke fungsi sosial

3. Adanya kasus voulantary yang meningkat, artinya bahwa dari tahun ke tahun mulai adanya perubahan kunjungan kline yang melakukan rehabilitasi secara suka rela walupun peningkatannya dikategorikan masih sebagian kecil

4. Semua warga binaan sudah diberdayakan melalui pascarehabilitasi dengan kegiatan vokasional melalui kerja sama dengan Dinas Sosial dan BLK

5. Mengapikasikan Bakat dan minat di tempat warga binaan bekerja

\section{PENUTUP}

\subsection{Kesimpulan}

Bedasarkan hasil penelitian di atas dengan variabel penelitaian yaitu Advokasi, Kemitraan dan Pemberdayaan terkait Upaya Rehabilitasi Penyalhgunan Narkoba maka dapat diambil beberapa kesimpulan sebagai berikut:

a. Badan Narkotika Nasional Provinsi Maluku Utara dalam Upaya Rehabilitasi Penyalahgunaan Narkoba di lihat dari Hasil Wawancara (Data Primer) dan data Sekunder diketahui BNNP Maluku Utara telah melakukan Advokasi dan mendapat dukungan dari 12 Institusi Pemerintah (IP) yaitu : (1) Lapas Kelas IIA Ternate, (2) RSUD Dr. Hasan Buesoirie, (3) Klinik Biddokes Polda Maluku Utara, (4) RS. Bhayangkara, (5) Klinik Pratama BNNP Maluku Utara, (6) Puskesmas Kalumata Ternate, (7) RSUD Sanana Kab. Kepulauan Sula, (8) RSUD Labuha Kab. Halmahera Selatan, (9) RSUD Maba Kab. Halmahera Timur, (10) Puskesmas Perawatan Obi, (11) RSUD Halmahera Barat, dan (12) RSUD Halmahera Tengah. Adapula dukungan dari 5 Komponen Masyarakat (KM) yaitu : (1) Klinik Annelevi, (2) LSM Rorano, (3) LSM Pena, (4) LSM Cengkih Institute, dan (5) LSM Mahuhahide.

b. Dari Hasil penelitian diketahui bentuk Kemitraan BNNP Maluku Utara dalam upaya rehabilitasi penyalahgunaan narkoba telah dirumuskan dalam surat Perjanjian Kerja Sama (PKS) antar institusi, dua diantaranya : (1) Perjanjian Kerjasama antara Bidang Rehabilitasi Badan Narkotika Nasional Provinsi Maluku Utara dengan Lembaga Pemasyarakat Kelas IIA Ternate Nomor:PKS/15/KA/RH.00.01/2019/BNNP tentang Dukungan Layanan Rehabilitasi bagi Pecandu dan Korban Penyalahgunaan Narkoba pada Lapas Kelas IIA Ternate. (2) Perjanjian Kerjasama antara Bidang Rehabilitasi BNN Provinsi Maluku Utara dengan Puskesmas Kalumata Nomor:PKS/13/I/Ka/Rh.00.01/2018/BNNP-MALUT tentang Dukungan Pelayanan Rehabilitasi bagi Pecandu dan Korban Penyalahgunaan Narkotika pada Fasilitas Pemerintah. Dalam surat Perjanjian ini Kedua Belah Pihak telah diatur Hak dan Kewajiban masing-masing dalam Upaya Rehabilitasi Penyalahgunan Narkoba.

c. Pemberdayaan yang dilakukan oleh BNNP Maluku Utara dalam upaya rehabilitasi penyalahgunaan narkoba adalah melakukan Penyuluhan dan Pelatihan. Memberikan Penyuluhan dengan Tujuan : (1) untuk memotivasi klien agar mengikuti program rehabilitasi, (2) memberikan informasi tentang layanan program rehabilitasi, (3) memberikan informasi tentang bahaya narkoba bagi kesehatan. Sedangkan pelatihan yang dilakukan yaitu pelatihan klien terkait ketrampilan yang di miliki sesuai dengan bakat dan minat masing-masing melalui Balai Latihan Kerja (BLK) dan Dinas Sosial, dengan tujuan (1) mendorong klien untuk mengasah ketrampilan dirinya seperti bekerja di bengkel dan pertanian selama menjalani pembinaan, (2) Mengapikasikan Bakat dan minat di tempat warga binaan bekerja. 
d. Dalam melaksanakan kegiatan rehabilitasi penyalahgunaan narkoba ada bebrapa Kendala yang ditemukan yaitu : (1) Kurangnya pengguna melapor diri secara sukarela, (2) Sumber daya yang terbatas, dan (3) Keterbatasan sarana prasarana untuk mengembangkan bakat klien (rumah damping)

\subsection{Saran}

1. Disarankan buat pihak BNN Provinsi Maluku Utara Bidang Rehabilitasi agar Terus melakukan penyuluhan tentang pentingnya mengikuti program rehabilitasi dan slalu memberikan motivasi kepada penguna Narkoba sehingga mereka mau mampu secara sukarela melakukan rehabilitasi medis maupun rehabilitasi sosial.

2. Disarankan kepada Kepala BNN Provinsi Maluku Utara agar menyediakan sarana parasarana terkait rumah damping untuk pengembangan bakat klien. Dan juga menyediakan alat transportasi seperti speed boad, kapal dan bus operasi rutin, mengingat Provinsi Maluku Utara merupakan wilayah kepulauan. Sehingga dengan alat transportasi tersebut upaya penanggulangan penyalahgunaan narkoba dapat dapat dijangkau pada daerah-daerah kepulaun yang lain. Sehingga BNNP Malut tidak slalu melaksankan kegiatan dalam Kota Ternate.

3. Disarankan Kepada pengguna narkoba agar slalu rutin mengikuti program rehabilitasi baik yang dilakukan oleh instansi pemerintah maupun LSM.

\section{DAFTAR PUSTAKA}

Badan Narkotika Nasional RI, 2009. Himpunan Peraturan Perundng-Undangan Narkotika, Psikotropika Beserta Konvensi PBB yang Mengaturnya. Jakarta.

Badan Narkotika Nasional RI, 2014. Modul Asesmen dan Rencana Terapi Gangguan Penggunaan Narkotika. Jakarta: Direktorat Penguatan Lembaga Rehabilitasi Instansi Pemerintah Deputi Bidang Rehabilitasi BNN.

Badan Narkotika Nasional RI, 2015. Standar Pelayanan Pascarehabilitasi. Jakarta: Direktorat Pascarehabilitasi Deputi Bidang Rehabilitasi.

Badan Narkotika Nasional RI. Profil BNN. https://bnn.go.id/profil diakses 16 September 2019

Badan Narkotika Nasional Provinsi Malut. Profil BNNP Maluku Utara Tahun 2018. Ternate Provinsi Maluku Utara.

Badan Narkotika Nasional Provinsi Malut, 2018. Surat Perjanjian Kerjasama antara Bidang Rehabilitasi BNN Provinsi Maluku Utara dengan Puskesmas Kalumata. Ternate Provinsi Maluku Utara.

Badan Narkotika Nasional Provinsi Malut, 2019. Surat Perjanjian Kerjasama antara Bidang Rehabilitasi Badan Narkotika Nasional Provinsi Maluku Utara dengan Lembaga Pemasyarakatan Kelas IIA Ternate. Ternate.

Departemen Kesehatan, 2009. Undang-Undang Republik Indonesia Nomor 35 Tahun 2009 Tentang Narkotika http://e-pharm.depkes.go.id/front/pdf/UU352009.pdf.

Kementerian Kesehatan RI, 2015. Rencana Strategis Kementerian Kesehatan Tahun 2015-2019. Jakarta. 
Kementerian Hukum dan Hak Asasi Manusia RI, 2011. Peraturan Pemerintah RI Nomor 25 Tahun 2011 Tentang Pelaksanaan Wajib Lapor Pecandu Narkotika. http://www.hukumonline.com/pusatdata/downloadfile/It4e783f16433f6/parent/It 4e783ec377207 Diakses 26 Agustus 2019.

Moleong, Lexy J, 2007. Metodologi Penelitian Kualitatif. Bandung: PT. Remaja Rosdakarya

Notoatmodjo, Soekidjo. 2003. Pendidikan dan Ilmu Perilku Kesehatan. Jakarta: Rineka Cipta.

Notoatmodjo, Soekidjo. 2010. Promosi Kesehatan Teori dan Aplikasi. Jakarta: Rineka Cipta.

Rama Nur Kurniawan. K, Strategi Promosi Kesehatan Terhadap Upaya Penanggulangan Penyalahgunaan Narkoba di Dinas Kesehatan Kabupaten Wajo. Jurnal Media Publikasi Promosi Kesehatan Indonesia (Januari, 2018) 21-24 Volume 1; Fakultas Kesehatan Masyarakat Universitas Muhammadiyah Palu.

Sadly, Hasan, 2000. Kamus Inggris Indonesia. Jakarta: Gramedia.

Saryono, 2008. Metodologi Penelitian Kesehatan, Penuntun Praktis bagi Pemula. Yogyakarta: Mitia Medika .

Sugiyono, 2018. Metode Penelitian Kuantitatif, Kualitatif, dan R\&D. Jakarta: Alfabeta. 